\title{
Pengujian Black Box pada Sistem Informasi Praktek Kerja Industri (PRAKERIN) dengan menggunakan Metode Boundary Value Analysis
}

\author{
Muhammad Indra Rizaldi ${ }^{1}$, Sandi Ramadhan ${ }^{2}$, Mochammad Noor Holik Majid ${ }^{3}$, Yulianti Yulianti ${ }^{4}$ \\ Teknik Informatika, Universitas Pamulang, Jl. Raya Puspitek No.46, Buaran, Serpong, Tangerang \\ Selatan, Banten, Indonesia, 15310 \\ e-mail : izallrizaldi@gmail.com ${ }^{1}$, sandiramadhan50@gmail.com², mnh.majid@gmail.com² \\ yulianti@unpam.ac.id ${ }^{4}$
}

Submitted Date: June $02^{\text {th }}, 2020$

Revised Date: July $07^{\text {th }}, 2020$
Reviewed Date: June $29^{\text {th }}, 2020$

Accepted Date: July $31^{\text {st }}, 2020$

\begin{abstract}
Praktek Kerja Industri (PRAKERIN) information system is a system used to record grades and other student data relating to the implementation of work practices in industry. This information system must be error free. If an error occurs can cause losses to stakeholders. To provide assurance that the information system developed has been free from errors, it is necessary to test. Testing is one level of the program implementation process that must be passed in order that an error can be found. Tests that can be said to be good are if the tests were initially found no errors and then errors can be found, even if only a small error. In testing the Praktek Kerja Industri (PRAKERIN) information system it is proposed as a Black Box. Black Box testing has various techniques. Of the many testing methods currently available, the current testing will use the Boundary Value Analysis method. The technique of determining the limits that exist in the lower and upper values to be able to produce the actual value. The test results show that the information system developed has been error free and has good quality.
\end{abstract}

Keywords: Boundary Value Analysis; Application Testing; Program Testing; Black Box

\section{Abstrak}

Sistem informasi Praktek Kerja Industri (PRAKERIN) merupakan sistem yang digunakan untuk mencatat nilai dan data-data siswa lainnya yang berhubungan dengan pelaksanaan praktik kerja di industri. Sistem informasi ini harus bebas dari kesalahan. Jika terjadi kesalahan dapat menyebabkan kerugian pada stakeholder. Untuk memberikan jaminan bahwa sistem informasi yang dikembangkan telah bebas dari keslaahan, maka perlu dilakukan pengujian. Pengujian adalah salah satu tingkatan proses pelaksanaan program yang harus dilalui bertujuan agar suatu kesalahan dapat ditemukan. Pengujian yang dapat dikatakan baik ialah apabila pengujian tersebut yang mulanya tidak ditemukan kesalahan kemudian dapat ditemukan kesalahan, meski hanya kesalahan kecil. Pada pengujian sistem informasi Praktek Kerja Industri (PRAKERIN) diusulkan secara Black Box. Pada pengujian Black Box memiliki teknik yang beragam. Dari sekian banyaknya metode pengujian yang ada saat ini, pada pengujian saat ini akan menggunakan metode Boundary Value Analysis. Teknik menentukan batasan yang ada pada nilai bawah dan atas untuk dapat menghasilkan nilai yang sebenarnya. Hasil pengujian menunjukkan bahwa sistem informasi yang dikembangkan telah bebas dari kesalahan dan memiliki kualitas yang baik.

Kata Kunci: Analisis Nilai Batas; Pengujian Aplikasi; Pengujian Program; Black Box

\section{Pendahuluan}

Pembuat program harus mempersiapkan waktu khusus untuk melakukan pengujian agar kesalahan atau kekurangan pada program komputer yang dibuat dapat diketahui sejak pertama dan dapat diperbaiki segera. Pengujian program komputer benar-benar sangat dibutuhkan untuk memastikan bahwa program yang dibuat telah sesuai harapan atau tidak. Pengujian program komputer penting dilakukan untuk menjamin bebas dari kesalahan dan tidak akan menimbulkan hal-hal 
yang merugikan pada saat digunakan (Ningrum, Suherman, Aryanti, Prasetya, \& Saifudin, 2019).

Sistem informasi Praktek Kerja Industri (PRAKERIN) merupakan sistem yang digunakan untuk mencatat nilai dan data-data siswa lainnya yang berhubungan dengan pelaksanaan praktik kerja di industri. Sistem informasi ini sangat penting dan harus bebas dari kesalahan agar tidak merugikan siswa. Jika ada kesalahan pemberian nilai menjadi lebih rendah dari yang sebenarnya dapat menyebabkan kerugian pada siswa.

Untuk menjamin kualitas sistem informasi Praktek Kerja Industri (PRAKERIN), maka perlu dilakukan pengujian. Kepuasan pengguna tergantung pada kualitas perangkat lunak yang diberikan, sehingga kualitas perangkat lunak perlu dijaga dengan berbagai alasan (Cholifah, Yulianingsih, \& Sagita, 2018). Bagian penting pengembangan program yang menjadi elemen tak dapat dipisahkan dari ruang lingkup pengembangan program komputer ialah pengujian. Pengembangan program komputer mencakup perencanaan, analisa kebutuhan, mendesain program, melakukan pengkodean program, pengujian, dan perawatan. Pengujian termasuk bagian dari siklus hidup pemgembangan perangkat lunak yang tidak dapat dipisahkan (Shi, 2010).

Beberapa strategi pengujian program telah dimuat dalam berbagai referensi. Pengujian program komputer sangat penting karena memiliki implikasi terhadap kualitas program komputer yang dikembangkan (Myres, Badgett, \& Sandler, 2012). Semua pengujian harus memiliki karakter umum yakni (1) Pengujian akan dimulai dari tingkatan modul dan menuju ke arah penggabungan sistem berbasis komputer; (2) Teknik pengujian harus disesuaikan pada item-item dengan waktu yang berbeda; (3) Pengujian dikerjakan oleh pembuat program namun untuk pengerjaan yang cukup besar maka pengujian akan dilakukan oleh tim pengujian yang independen; (4) Pengujian serta debugging ialah merupakan kegiatan yang berbeda, namun debugging harus selalu dilakukan pada setiap pengujian.

Pengujian yang dilakukan harus dirancang dengan baik agar dapat menemukan kesalahan secara sistematis dan dapat diperbaiki dalam waktu yang singkat (Kurniawan, Maulana, Sukma, Keumala, \& Saifudin, 2020). Pengujian yang dilakukan tidak lengkap dan efektif dapat menimbulkan masalah dan menyebabkan kerugian ketika software digunakan (Rosalina, Rassi, Hadi, Ubaidillah, \& Desyani, 2020). Pada pengujian sistem informasi Praktek Kerja Industri
(PRAKERIN) ini akan dilakukan secara Black Box menggunakan teknik Boundary Value Analysis (BVA). Pengujian Black Box merupakan pengujian yang dilakukan dengan memverifikasi dan memvalidasi keluaran hasil eksekusi berdasarkan data masukan yang diberikan dan memeriksa fungsional dari perangkat lunak (Krismadi, et al., 2019).

Pengujian perangkat lunak mencakup aktifitas Verification and Validation (V\&V). Verifikasi merujuk kepada kelompok pelaksana agar memastikan program telah mengimplementasikan fungsi secara jelas. Sedangkan validasi merujuk pada kelompok yang berbeda dari pelaksanaan yang memastikan bahwa program yang sudah dibuat bisa diketahui kepada kebutuhan pelanggan. SQA (Software Quality Assurance) dirangkum dari banyaknya kegiatan $\mathrm{V} \& \mathrm{~V}$ (Verification and Validation).

\section{Metodologi Penelitian}

Penelitian ini ditujukan untuk menjamin bahwa sistem informasi Praktek Kerja Industri (PRAKERIN) yang dikembangkan telah memenuhi persyaratan dan memiliki kualitas yang baik. Untuk memenuhi tujuan penelitian dilakukan pengujian. Pengujian sangat diperlukan dalam sistem informasi untuk memastikan aplikasi yang dikembangan telah memenuhi persyaratan teknis dan bisnis yang diharapkan sebelum diserahkan kepada pengguna (customer) (Febrian, Ramadhan, Faisal, \& Saifudin, 2020). Tujuan dari pengujian adalah untuk memastikan bahwa sistem yang dihasilkan sesuai dengan kebutuhan dan layak untuk digunakan (Arwaz, Putra, Putra, Kusumawijaya, \& Saifudin, 2019).

Memperhatikan pentingnya pengujian dalam pengembangan program komputer, maka pengujian tidak dapat dihindari. Pengujian harus dilaksanakan dengan baik sesuai prosedurnya. Sehingga dalam pengembangan program komputer harus diiringi aktivitas pengujian untuk memberikan jaminan kualitasnya (Liana, 2015).

\subsection{Black Box Testing}

Metode pengujian Black Box adalah pengujian yang memverifikasi hasil eksekusi aplikasi berdasarkan masukan yang diberikan (data uji) untuk memastikan fungsional dari aplikasi sudah sesuai dengan persyaratan (requirement) (Febrian, Ramadhan, Faisal, \& Saifudin, 2020). Pengujian Black box hanya memverifikasi dan memvalidasi nilai keluaran berdasarkan nilai masukan yang diberikan. Dalam pengujian Black 
Box tidak membutuhkan pengetahuan tentang kode program yang pakai (Latif, 2015).

Penguji dapat mengartikan sebuah kondisi masukan serta melakukan sebuah pengujian bagi perincian peranan software. Serta Black Box Testing ini tidak menjadi jalan keluar pengganti atas White Box Testing namun kepada penambahan pengujian apa sajakah yang tidak terdapat pada White Box Testing.

Pengujian black box ini menitik beratkan pada fungsi sistem (Syaban \& Bunyamin, 2015). Teknik Black Box Testing lebih mengarah agar mendapatkan hal seperti:

1. Peran yang tidak ada.

2. Antarmuka yang tidak benar.

3. Akses ke database dan bentuk data yang tidak benar.

4. Penampilan yang tidak benar.

5. Pendefinisian nilai batas atas serta mendefinisikan nilai batas bawah yang tidak benar. berikut:

Pengujian dibuat karena adanya pertanyan

1. Bagaimana pengujian fungsi agar bisa dikatakan benar?

2. Masukan yang bagaimana yang dianggap benar dalam pengujian agar dapat menjadi bahan?

3. Apakah masukan khusus membuat sistem menjadi rawan?

4. Bagaimana kumpulan data dapat dipisahkan?

5. Berapa banyak sistem dapat mengerjakan jumlah?

6. Resiko apa yang dapat operasi system kerjakan untuk menggabungkan data secara rinci?

Banyak metode atau cara untuk melakukan Black Box Testing, di antaranya:

1. Partisi Kesetaraan.

2. Analisis Nilai Batas/Pengujian Batas.

3. Pengujian Perbandingan.

4. Pengujian Sampel.

5. Pengujian Kekokohan.

6. Pengujian Perilaku.

7. Pengujian Kebutuhan.

8. Pengujian Kinerja.

9. Pengujian Daya Tahan.
10.Pengujian Hubungan Sebab \& Akibat.

\subsection{Boundary Value Analysis}

Boundary Value Analysis merupakan teknik pengujian program komputer di mana pengujian dirancang untuk mencakup perwakilan dalam kisaran batas nilai masukan (Pratama, Ristianto, Prayogo, Nasrullah, \& Saifudin, 2020). Boundary Value Analysis merupakan salah satu jenis teknik pengujian Black Box yang melakukan pengujian pada batas atas dan batas bawah dari suatu nilai yang dimasukkan ke dalam aplikasi (Zuriati, Widyawati, Sitanggang, \& Buowo, 2018). Terdapat sejumlah landasan yang melandasi Boundary Value Analysis (BVA) ini, yakni:

1. Banyaknya masukan yang mengalami kesalahan.

2. Membedakan kasus pengujian yang menguji batasan nilai masukan diijinkan BVA.

3. BVA ialah tambahan dari partisi kesetaraan. Lebih kepada menentukan bagian-bagian di dalam ruang ekivalen pada elemen tepi batas dari ruang tersebut.

Berikut ini contoh penentuan nilai Boundary Value Analysis (BVA):

a. Jarak yang diberi batasan pada a \& b jadi, $\{$ a$1\}, a,\{a+1\},\{b-1\}, b,\{b+1\}$.

b. Apabila masukan mengisyaratkan $\mathrm{n}=$ nilai lalu uji menggunakan sebanyak $\{\mathrm{n}-1\}$, $\mathrm{n},\{\mathrm{n}+1\}$.

c. Pada keadaan keluaran mengaplikasikan dua metode sebelumnya (buat tabel pengujian hasil keluaran dari nilai maks dan min).

d. Pada program mempunyai jangkauan jika bentuk datanya internal (contohnya ukuran pada buffer, dan batas pada array) batas cakupan diuji menggunakan data masukan.

Aplikasi BVA secara umum dapat dikerjakan secara generik. Bentuk pengaplikasian secara mendasar ialah untuk menjaga sebuah variable agar terletak pada nilai nominalnya (normal atau rata-rata) dan dengan nilai ekstrim yang diisi memberi ijin variabel lain.

Pengujian dilakukan pada form masukan data guru menggunakan pengujian Black Box dengan metode Boudary Value Analysis. Antarmuka aplikasi yang diuji ditunjukkan pada Gambar 1 dan Gambar 2. 


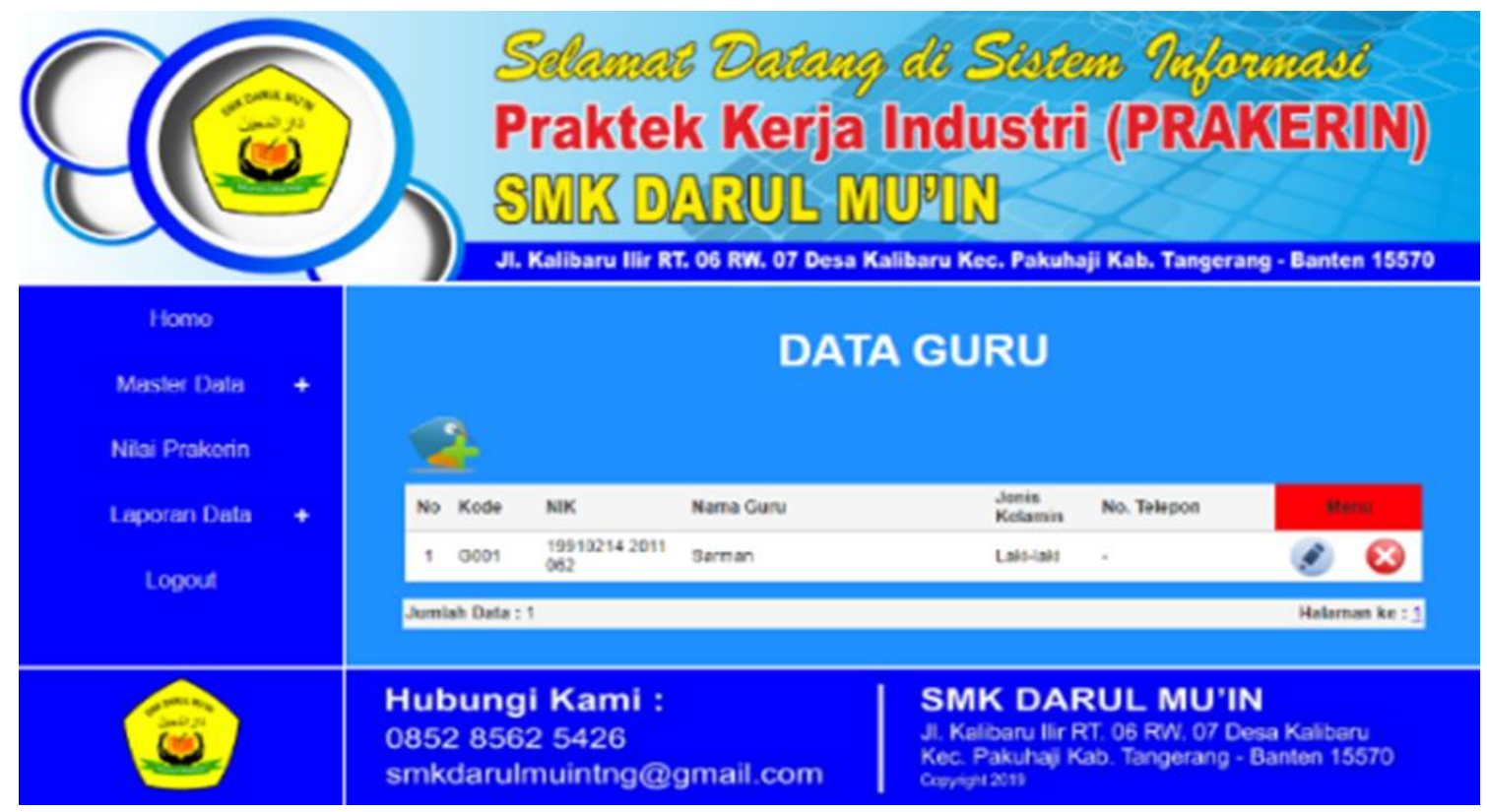

Gambar 1 Form Keluaran Data Guru

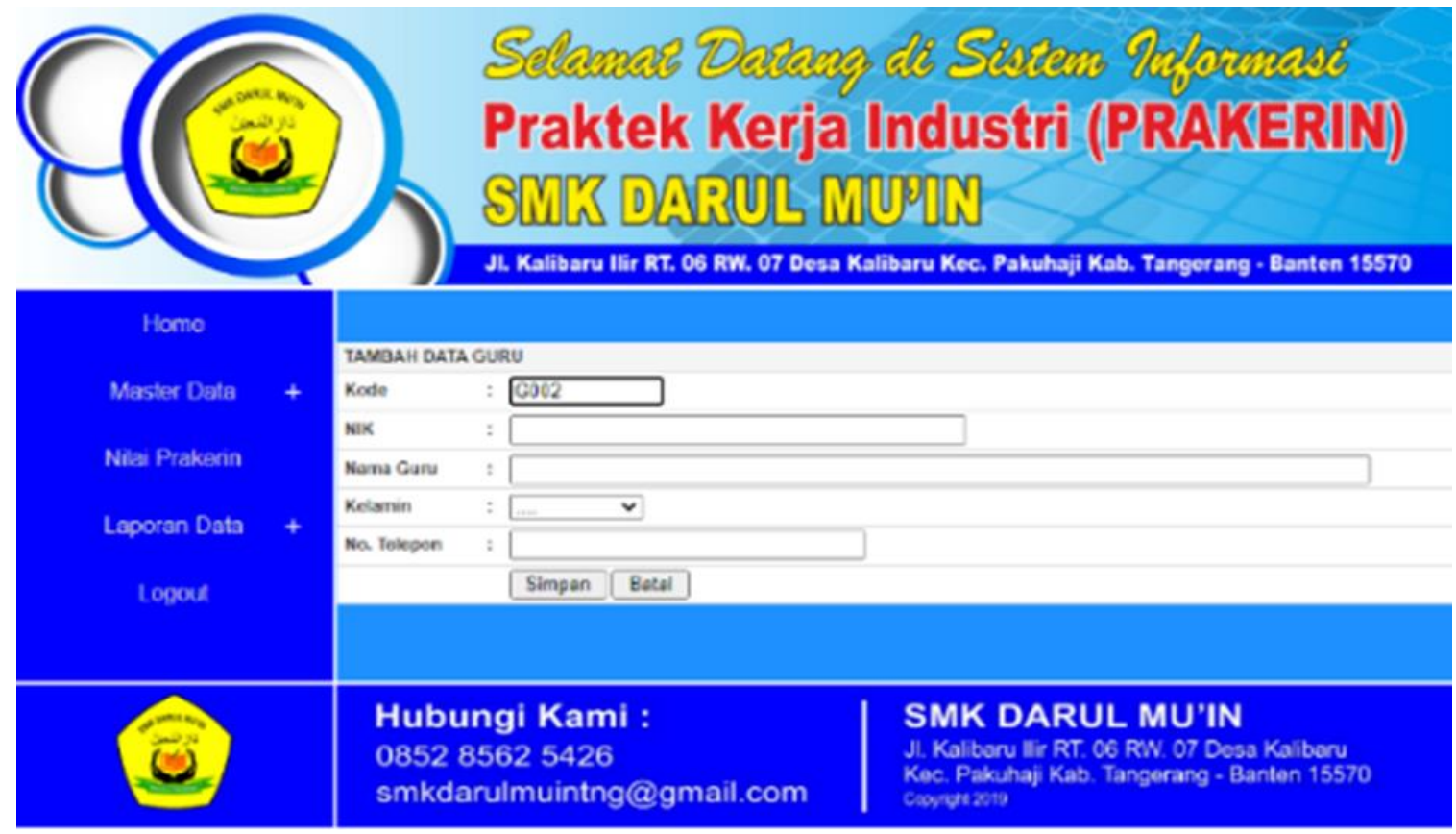

Gambar 2 Form Masukan Data Guru

Tabel 1 Rancangan Pengujian

\begin{tabular}{|c|l|l|}
\hline $\begin{array}{c}\text { Test } \\
\text { Id }\end{array}$ & \multicolumn{1}{|c|}{ Deskripsi Pengujian } & \multicolumn{1}{|c|}{$\begin{array}{c}\text { Hasil yang } \\
\text { Diharapkan }\end{array}$} \\
\hline \multirow{3}{\text{G01}}{} & $\begin{array}{l}\text { Pengujian dengan kode guru tidak terdaftar } \\
\text { - Admin memasukkan kode guru (Kode guru G + 3 digit angka) G001 } \\
\text { - Admin memasukkan NIK, Nama Guru, Jenis Kelamin, No. Telpon } \\
\text { - Kemudian klik tombol simpan }\end{array}$ & $\begin{array}{l}\text { Tampil Pop Up } \\
\text { data berhasil } \\
\text { disimpan }\end{array}$ \\
\hline
\end{tabular}




\begin{tabular}{|l|l|l|}
\hline G02 & $\begin{array}{l}\text { Pengujian dengan kode guru tidak terdaftar } \\
\text { - Admin memasukkan kode guru (Kode guru G }+<3 \text { digit angka) G01 } \\
\text { - Admin memasukkan NIK, Nama Guru, Jenis Kelamin, No. Telpon } \\
\text { - Kemudian klik tombol simpan }\end{array}$ & $\begin{array}{l}\text { Tampil Pop Up } \\
\text { error atau kode } \\
\text { guru salah }\end{array}$ \\
\hline G03 & $\begin{array}{l}\text { Pengujian dengan kode guru tidak terdaftar } \\
\text { - Admin memasukkan kode guru (Kode guru G }+>3 \text { digit angka) G0001 } \\
\text { - Admin memasukkan NIK, Nama Guru, Jenis Kelamin, No. Telpon } \\
\text { - Kemudian klik tombol simpan }\end{array}$ & $\begin{array}{l}\text { Tampil Pop Up } \\
\text { error atau kode } \\
\text { guru salah }\end{array}$ \\
\hline G04 & $\begin{array}{l}\text { Pengujian dengan kode guru terdaftar } \\
\text { - Admin memasukkan kode guru (Kode guru G + 3 digit angka) G001 } \\
\text { - Admin memasukkan NIK, Nama Guru, Jenis Kelamin, No. Telpon } \\
\text { - Kemudian klik tombol simpan }\end{array}$ & $\begin{array}{l}\text { Tampil Pop Up } \\
\text { kode guru sudah } \\
\text { digunakan }\end{array}$ \\
\hline
\end{tabular}

\section{Hasil dan Pembahasan}

Pengujian sistem informasi Praktek Kerja Industri (PRAKERIN) dilaksanakan sesuai rancangan uji kasus (test case) yang telah dibuat. Setiap pelaksanaan uji kasus (test case) dicatat hasil pengujiannya dan status (kesimpulan) hasilnya. Dokumentasi pelaksanaan pengujian diperlukan untuk analisa dan evaluasi pelaksanaan pengujian. Hasil pengujian ditunjukkan pada Tabel 2.

Tabel 2 Hasil Pengujian

\begin{tabular}{|c|c|c|c|c|}
\hline $\begin{array}{l}\text { Test } \\
\text { Id }\end{array}$ & Deskripsi Pengujian & $\begin{array}{l}\text { Hasil yang } \\
\text { Diharapkan }\end{array}$ & $\begin{array}{c}\text { Hasil } \\
\text { Pengujian }\end{array}$ & Status \\
\hline G01 & $\begin{array}{l}\text { Pengujian dengan kode guru tidak terdaftar } \\
\text { - Admin memasukkan kode guru (Kode guru G }+3 \text { digit } \\
\text { angka), yaitu G001 } \\
\text { - Admin memasukkan NIK, Nama Guru, Jenis Kelamin, } \\
\text { No. Telpon } \\
\text { - Kemudian klik tombol simpan }\end{array}$ & $\begin{array}{l}\text { Tampil Pop } \\
\text { Up data } \\
\text { berhasil } \\
\text { disimpan }\end{array}$ & $\begin{array}{l}\text { Tampil Pop } \\
\text { Up data } \\
\text { berhasil } \\
\text { disimpan }\end{array}$ & $\mathrm{Ok}$ \\
\hline G02 & $\begin{array}{l}\text { Pengujian dengan kode guru tidak terdaftar } \\
\text { - Admin memasukkan kode guru (Kode guru } \mathrm{G}+<3 \\
\text { digit angka), yaitu G01 } \\
\text { - Admin memasukkan NIK, Nama Guru, Jenis Kelamin, } \\
\text { No. Telpon } \\
\text { - Kemudian klik tombol simpan }\end{array}$ & $\begin{array}{l}\text { Tampil Pop } \\
\text { Up error atau } \\
\text { kode guru } \\
\text { salah }\end{array}$ & $\begin{array}{l}\text { Tampil Pop } \\
\text { Up error } \\
\text { atau kode } \\
\text { guru salah }\end{array}$ & Ok \\
\hline G03 & $\begin{array}{l}\text { Pengujian dengan kode guru tidak terdaftar } \\
\text { - Admin memasukkan kode guru (Kode guru G + > } 3 \\
\text { digit angka), yaitu G0001 } \\
\text { - Admin memasukkan NIK, Nama Guru, Jenis Kelamin, } \\
\text { No. Telpon } \\
\text { - Kemudian klik tombol simpan }\end{array}$ & $\begin{array}{l}\text { Tampil Pop } \\
\text { Up error atau } \\
\text { kode guru } \\
\text { salah }\end{array}$ & $\begin{array}{l}\text { Tampil Pop } \\
\text { Up error } \\
\text { atau kode } \\
\text { guru salah }\end{array}$ & $\mathrm{Ok}$ \\
\hline G04 & $\begin{array}{l}\text { Pengujian dengan kode guru terdaftar } \\
\text { - Admin memasukkan kode guru (Kode guru G + } 3 \text { digit } \\
\text { angka), yaitu G001 } \\
\text { - Admin memasukkan NIK, Nama Guru, Jenis Kelamin, } \\
\text { No. Telpon } \\
\text { - Kemudian klik tombol simpan }\end{array}$ & $\begin{array}{l}\text { Tampil Pop } \\
\text { Up kode guru } \\
\text { sudah } \\
\text { digunakan }\end{array}$ & $\begin{array}{l}\text { Tampil Pop } \\
\text { Up kode } \\
\text { guru sudah } \\
\text { digunakan }\end{array}$ & $\mathrm{Ok}$ \\
\hline
\end{tabular}

Pengujian Black Box menggunakan Boudary Value Analysis dapat memberikan gambaran bagaimana serangkaian skenario diujikan untuk memperoleh nilai yang sebenarnya. Hasil pengujian dari 4 skenario yang semua dapat dilakukan dengan baik tanpa adanya kendala apapun. Pengujian ini dapat berjalan dengan lancar mencapai $100 \%$ dan dapat dilanjutkan untuk ke 
langkah berikutnya. Dengan dilakukannya pengujian, maka dapat memastikan bahwa aplikasi yang dibuat telah sesuai persyaratan yang telah ditetapkan. Pengujian ini juga memberikan jaminan bahwa aplikasi yang dibuat telah memiliki kualitas yang baik.

\section{Kesimpulan}

Berdasarkan pengujian Black Box menggunakan metode Boundary Value Analysis pada perolehan dari pengujian form data guru mendapat kesimpulan:

1. Salah satu metode yang mudah digunakan ialah metode Black Box Testing karena cukup memerlukan Batasan nilai atas dan bawah dari data yang diinginkan.

2. Pengujian dapat dihitung dengan memperkirakan banyaknya data yang akan diuji dengan jumlah field data masukan, kasus batasan nilai atas dan bawah yang memenuhi serta ketentuan masukan yang harus dipenuhi.

3. Fungsi masih dapat berjalan, diketahui setelah dilakukannya pengujian, tetapi data yang tersimpan tidak tepat disebakan oleh fungsi yang masih dapat menerima masukan data yang tidak sesuai.

4. Fungsi masukan data harus ditambahkan dengan proses persamaan data berdasarkan hasil uji untuk memastikan kesesuaian masukan data pada fungsi program yang diharapkan dengan metode BVA.

\section{Referensi}

Arwaz, A. A., Putra, K., Putra, R., Kusumawijaya, T., \& Saifudin, A. (2019). Pengujian Black Box pada Aplikasi Sistem Seleksi Pemenang Tender Menggunakan Teknik Equivalence Partitions. Jurnal Teknologi Sistem Informasi dan Aplikasi, 2(4), 130-134. doi:10.32493/jtsi.v2i4.3708

Cholifah, W. N., Yulianingsih, \& Sagita, S. M. (2018). Pengujian Black Box Testing Pada Aplikasi Action \& Strategy Berbasis Android Dengan Teknologi Phonegap. Jurnal String Vol. 3 No.2, 206-210.

Febrian, V., Ramadhan, M. R., Faisal, M., \& Saifudin, A. (2020). Pengujian pada Aplikasi Penggajian Pegawai dengan menggunakan Metode Blackbox. Jurnal Informatika Universitas Pamulang, 5(1), 61-66. doi:10.32493/informatika.v5i1.4340

Krismadi, A., Lestari, A. F., Pitriyah, A., Mardangga, I. W., Astuti, M., \& Saifudin, A. (2019). Pengujian Black Box berbasis Equivalence Partitions pada Aplikasi Seleksi Promosi
Kenaikan Jabatan. Jurnal Teknologi Sistem Informasi dan Aplikasi, 2(4), 155-161.

Latif, A. (2015). Implementasi Kriptografi Menggunakan Metode Advanced Encryption Standar (AES) Untuk Pengamanan Data Teks. Jurnal Ilmiah Mustek Anim, 4(2), 163-172.

Ningrum, F. C., Suherman, D., Aryanti, S., Prasetya, H. A., \& Saifudin, A. (2019). Pengujian Black Box pada Aplikasi Sistem Seleksi Sales Terbaik Menggunakan Teknik Equivalence Partitions. Jurnal Informatika Universitas Pamulang, 4(4), 125-130.

Pratama, B. P., Ristianto, I. B., Prayogo, I. A., Nasrullah, \& Saifudin, A. (2020). Pengujian Perangkat Lunak Sistem Informasi Penilaian Mahasiswa dengan Teknik Boundary Value Analysis Menggunakan Metode Black Box Testing. Journal of Artificial Intelligence and Innovative Applications, 1(1), 32-36.

Rosalina, A., Rassi, A. A., Hadi, G. Y., Ubaidillah, R., \& Desyani, T. (2020). Pengujian Black Box pada Sistem Informasi Penjualan HI Shoe Store Menggunakan Teknik Equivalence Partitions. Jurnal Informatika Universitas Pamulang, 5, 26-29. doi:10.32493/informatika.v5i1.3964

Syaban, R. M., \& Bunyamin, H. (2015). Pengembangan Sistem Informasi Pengelolaan Surat Masuk dan Keluar Berbasis Web di Dinas Sosial Tenaga Kerja dan Transmigrasi Kabupaten Garut Menggunakan Framework PHP. Jurnal Algoritma, 12(2), 301-311.

Zuriati, Z., Widyawati, D. K., Sitanggang, I. S., \& Buowo, A. (2018). Teknik Pengujian Boundary Value Analysis Pada Aplikasi Learning Management System Polinela. Jurnal TAM (Technology Acceptance Model) Volume 9, Nomor 2, 85-92. 